\title{
INFLUÊNCIA DA TEMPERATURA NOS RENDIMENTOS DOS PRODUTOS DA PIRÓLISE DO ENDOCARPO DO OURICURI (Syagrus coronata (Mart) Becc.)
}

\section{MEILI*, L. E. R. SANTOS, R. DOS SANTOS, R. G. S. A. ANDRADE, J. I. SOLETTI}

Universidade Federal de Alagoas, Centro de Tecnologia

*e-mail: lucas.meili@ctec.ufal.br

\begin{abstract}
RESUMO
O licuri ou ouricuri, Syagrus coronata (Mart) Becc., é uma palmeira cuja distribuição se estende até o litoral brasileiro, cresce bem nas restingas baianas, mas tem preferência pelas regiões de caatinga, crescendo em áreas altamente pedregosas e castigadas pelo sol, até outras com melhores condições de solo, tornando-se parte da vegetação predominante de algumas regiões. Um estudo realizado em Buíque (PE), mostrou que a importância do ouricuri está relacionada predominantemente ao uso da amêndoa. Como forma de aproveitar o endocarpo (material lignificado que envolve a amêndoa), este trabalho objetiva o estudo da pirólise do endocarpo do ouricuri, agregando valor, por meio da geração de produtos com potencial comercial. Avaliou-se o rendimento dos produtos obtidos para diferentes temperaturas finais $\left(400,500,600\right.$ e $\left.700^{\circ} \mathrm{C}\right)$, com taxa de aquecimento de $10^{\circ} \mathrm{C} / \mathrm{min}$ e o tempo de residência de $2 \mathrm{~h}$ (duas horas), além de vácuo constante de $50 \mathrm{mmHg}$, para controlar a atmosfera do reator, evitando queima. Com o aumento de temperatura, o rendimento em carvão diminuiu devido à decomposição dos constituintes do endocarpo. Por sua vez o rendimento em gases foi crescente com o aumento da temperatura e o rendimento da mistura líquida aumentou na faixa de $400^{\circ} \mathrm{C}$ a $600^{\circ} \mathrm{C}$, mas decresceu à temperatura de $700^{\circ} \mathrm{C}$, devido ao craqueamento dos vapores condensáveis.
\end{abstract}

\section{INTRODUÇÃO}

A biomassa vem ganhando espaço na matriz energética mundial, devido a sua conversão em produtos líquidos, sólidos e gasosos, através de processos de conversão físicos, químicos e biológicos (FIGUEIREDO, 2011). Segundo Cortez, Lora e Ayarza (2008), ela tem origem em resíduos sólidos urbanos (animais, vegetais, industriais e florestais) e, voltada para fins energéticos, abrange a utilização desses vários resíduos 
para a geração de fontes alternativas de energia. A biomassa lignocelulósica é constituída por celulose, hemicelulose, além de lignina e pequenas quantidades de outras substâncias, como extrativos e cinzas, os quais estão contidos na parede celular das plantas (SANTOS, 2011).

A aplicação do processo de pirólise para transformação da biomassa em carvão e outros produtos, derivados da decomposição da hemicelulose, celulose e lignina - os principais constituintes da biomassa lignocelulósica, tem sido muito frequente nos dias atuais, devido a grandes discussões a respeito dos impactos ambientais gerados pelo descarte inadequado desses resíduos. Rufino et al. (2008) investigaram do ponto de vista etnobotânico a importância do ouricuri (Syagrus coronata) e do babaçu (Orbignya phalerata) em uma comunidade no município de Buíque, Pernambuco. Foram citadas sete categorias de uso: alimento do homem; alimento de animais domésticos; alimento de animais silvestres; construção; artesanato; combustível; medicinal. Apesar dessa diversidade de usos, verificaram que a importância das duas espécies está relacionada predominantemente ao aproveitamento da amêndoa.

O licuri ou ouricuri, Syagrus coronata (Mart) Becc., tem distribuição no norte de Minas Gerais, na Bahia, Pernambuco, Sergipe e Alagoas. Embora sua distribuição se estenda até o litoral brasileiro e cresça bem nas restingas baianas, tem preferência pelas caatingas, crescendo em áreas altamente pedregosas e castigadas pelo sol, até áreas com melhores condições de solo, tornando-se a vegetação predominante de algumas regiões (NOBLICK, 1986 apud RAMALHO, 2008). Esta palmeira possui um tronco com altura variando de 6-10m. Os cachos de licuri têm em média 1357 frutos, com comprimento e diâmetro médios de $2,0 \mathrm{~cm}$ e $1,4 \mathrm{~cm}$, respectivamente (CREPALDI et al. 2001). Seu fruto é dividido em três camadas distintas, sendo elas, epicarpo, mesocarpo e endocarpo, que juntas formam o pericarpo. $\mathrm{O}$ epicarpo é fibroso, externamente liso e desprovido de pelos, conforme Figura 1A. O mesocarpo quando maduro tem coloração amarelada ou alaranjada é mucilaginoso, fibroso de acordo com a Figura 1A, enquanto o endocarpo é lignificado, possui coloração amarronzada e tem formato e tamanho variável de acordo com as características morfológicas do fruto, variando de globoso a elipsóide. Na sua superfície encontram-se as fibras mesocárpicas distribuídas longitudinalmente segundo as Figuras $1 \mathrm{~B}$ e $\mathrm{C}$ (SANTOS-MOURA, 2013).

Figura 1 - Morfologia do fruto de $S$. coronata. (A) Fruto, (B) Corte longitudinal do fruto, (C) Diásporo.

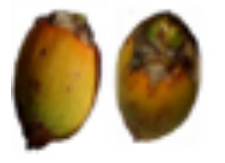

(A)

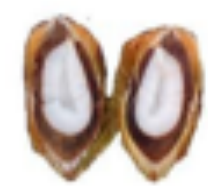

(B)

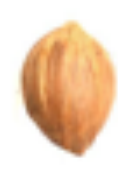

(C)
Fonte: Adaptada de SANTOS-MOURA, 2013.

Através do processo de pirólise, que de acordo com Bridgwater (2012), consiste na decomposição térmica que converte combustíveis sólidos, como a biomassa, na ausência de oxigênio, em carvão (sólido), vapores de hidrocarbonetos condensáveis (chamados de "óleo" para uso após a condensação) e gases não-condensáveis (por exemplo, $\mathrm{CO}, \mathrm{CO}_{2}, \mathrm{H}_{2}$ e $\mathrm{CH}_{4}$, um combustível para uso imediato), pode-se aproveitar o endocarpo do ouricuri, aplicando esse processo, agregando dessa forma valor a esse material.

Os produtos obtidos por meio da pirólise podem ter as seguintes aplicações: o 
carvão obtido pode ser utilizado como combustível, ser aplicado ao solo como um meio de melhorar a produtividade e para armazenamento de carbono, sendo então denominado de biocarvão (LEHMANN; JOSEPH, 2009) ou ainda passar pelo processo de ativação para obtenção de carvão ativado. A mistura líquida que é composta por duas fases - uma aquosa chamada de extrato ácido, é empregada na produção de inseticidas e fungicidas, adubo natural e na produção de combustíveis leves. A outra fase, orgânica denominada bioóleo ou óleo pirolítico, pode ser usado diretamente como combustível em sistemas estacionários de geração de energia, na substituição de fenol petroquímico ou pode ser fracionado para produzir derivados da química fina, entre outras aplicações (BIOWARE, 2014).

As condições de pirólise, como a temperatura, a taxa de aquecimento, a granulometria, o tempo de residência afetam o rendimento dos produtos de pirólise. A composição química da biomassa também tem um papel importante na distribuição dos produtos da pirólise. Assim, cada material exibe uma característica particular quando é pirolisado, em decorrência da proporção dos componentes que os constituem (SANTOS, 2011). O objetivo deste trabalho foi verificar a influência da temperatura no rendimento dos produtos obtidos com a carbonização do endocarpo do ouricuri.

\section{MATERIAIS E MÉTODOS}

\subsection{Obtenção e preparação da matéria- prima}

O material utilizado foi coletado na região metropolitana de Maceió e depois de retirado o mesocarpo foi armazenado no Laboratório de Sistemas de Separação e Otimização de Processos (LASSOP) localizado na Universidade Federal de Alagoas (UFAL).

As amostras, compostas pelo endocarpo e amêndoas foram moídas inicialmente em um moinho de rolo e, então, foi feita a limpeza com retirada dessas amêndoas. Em seguida, os endocarpos foram classificados em peneiras, sendo utilizadas as partículas retidas entre as peneiras de $6,3 \mathrm{~mm}$ e $9,5 \mathrm{~mm}$, de acordo com a Figura 2.

\subsection{Caracterização da matéria-prima}

Para determinação das temperaturas finais de pirólise foi realizada uma análise termogravimétrica do endocarpo do ouricuri. A análise foi realizada no Laboratório de Síntese de Catalisadores (LScat), localizado na Universidade Federal de Alagoas (UFAL). Foi conduzida em um equipamento Shimadzu TGA- $60 \mathrm{H}$, numa faixa de temperatura de 28 a $1000^{\circ} \mathrm{C}$, com taxa de aquecimento de $10^{\circ} \mathrm{C} \cdot \mathrm{min}^{-1}$, sob vazão de nitrogênio de 50 $\mathrm{mL} \cdot \mathrm{min}^{-1}$, a fim de verificar as perdas de massa do endocarpo do ouricuri (in natura) com o aumento da temperatura. Foi utilizado cadinho de alumina e uma massa de amostra de $21,70 \mathrm{mg}$

\subsection{Pirólise}

O aparato experimental consiste de um forno tubular Jung modelo LT6 2010, com sistema de resfriamento para coleta do bioóleo composto por dois condensadores de vidro consecutivos, estando o último conectado a um kitassato e este a uma bomba de vácuo. Os gases eram liberados para um recipiente contendo água, a fim de que parte fosse retido. Para a refrigeração dos condensadores foi utilizado um banho termostatizado modelo TE - 184. A Figura 3 mostra o aparato experimental.

Os ensaios foram realizados com temperaturas finais de $400,500,600$ e $700^{\circ} \mathrm{C}$, com taxa de aquecimento de $10^{\circ} \mathrm{C} / \mathrm{min}$ e 
tempo de residência de $2 \mathrm{~h}$. A temperatura do banho foi mantida a $3^{\circ} \mathrm{C}$. A massa inicial usada em cada ensaio foi $500 \mathrm{~g}$.

Após o resfriamento do forno, o carvão foi removido e pesado. Assim como o kitassato com a fase aquosa e o bioóleo, para obtenção da massa líquida por diferença (com a massa do kitassato vazio).

Os rendimentos dos produtos da pirólise foram calculados de acordo com as seguintes Equações 1, 2 e 3:

Rendimento do sólido $\left(\mathrm{R}_{\mathrm{s}}\right)$ :

$$
R_{s}=\frac{M_{s f}}{M_{i}} \times 100
$$

Rendimento líquido $\left(\mathrm{R}_{1}\right)$ :

$$
R_{l}=\frac{M_{l f}}{M_{i}} \times 100
$$

Rendimento gasoso $\left(\mathrm{R}_{\mathrm{g}}\right)$ :

$$
R_{g}=100-\left(R_{s}+R_{l}\right)
$$

Figura 2 - Material utilizado na pirólise.

Fonte: Autor (2015).

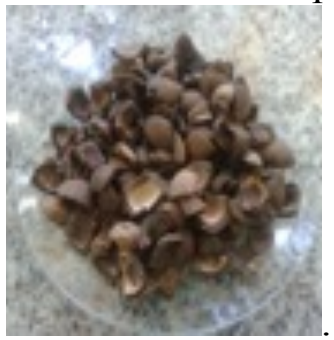

Figura 3 - (A) Aparato experimental para realização da pirólise (B) sistema de condensação.

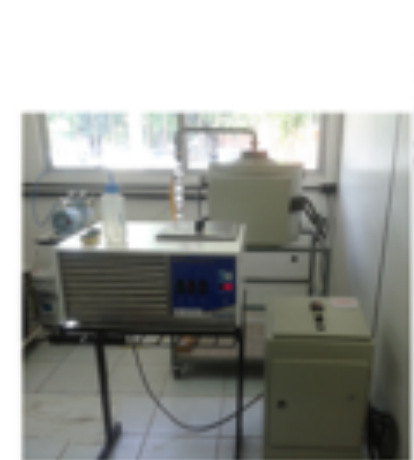

(A)

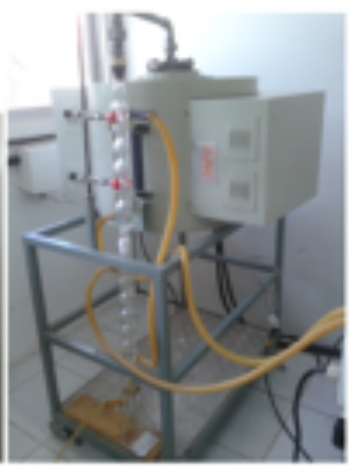

(B)
Fonte: Autor (2015).

\section{RESULTADOS E DISCUSSÃO}

\subsection{Curva TG/DTG do Endocarpo do ouricuri (Syagrus coronata (Mart) Becc.)}

Como dito anteriormente a composição química da biomassa tem um papel importante na distribuição dos produtos da pirólise. Os principais componentes da biomassa lignocelulósica são a celulose, a hemicelulose e a lignina.

A curva da análise termogravimétrica para o endocarpo do ouricuri (in natura) e a derivada da curva, TG e DTG, respectivamente são mostradas na Figura 4.

Figura 4 - Curva TG e DTG do endocarpo do ouricuri (in natura) a taxa de aquecimento de $10^{\circ} \mathrm{C} / \mathrm{min}$.

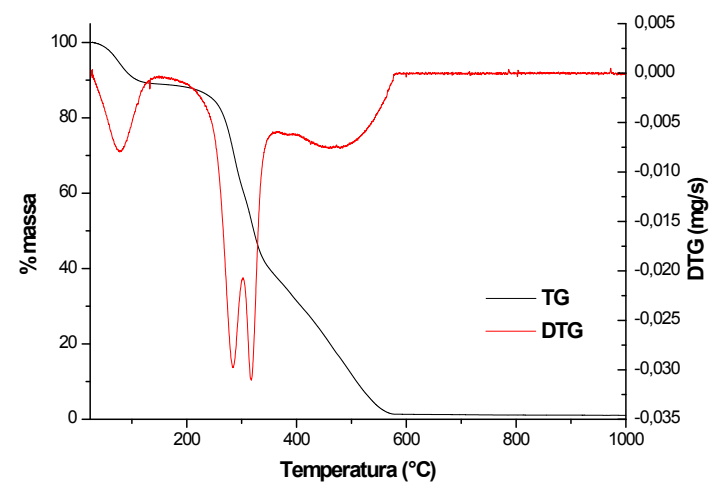

Através da Figura 4 pode-se perceber a presença do primeiro pico, no intervalo de 28 
- $150^{\circ} \mathrm{C}$, que pode ser atribuído a desidratação do endocarpo do ouricuri. Houve uma redução na massa de aproximadamente $11 \%$. Seguindo-se com a elevação de temperatura observa-se a ocorrência de dois picos. Este comportamento foi também observado em estudo realizado por Tsamba, Yang e Blasiak (2006) que estudaram a degradação térmica por meio da termogravimetria de casca de coco e de castanha de caju e compararam com pellets de madeira. Os resultados mostraram que os perfis de pirólise foram diferentes do perfil da biomassa lenhosa, pois apresentava dois picos diferentes, em vez de um pico de sobreposição, para a hemicelulose e celulose.

Segundo Li et al. (2008) já foi confirmado que a lignina começa decompondo-se a baixas temperaturas (160-170 $\left.{ }^{\circ} \mathrm{C}\right)$ e continua a decompor-se a baixa taxa até cerca de $900{ }^{\circ} \mathrm{C}$. A hemicelulose é o segundo componente a iniciar a decomposição, seguido da celulose, no intervalo de temperatura de 200 a $400^{\circ} \mathrm{C}$. Ainda segundo Tsamba, Yang e Blasiak (2006) os primeiros picos encontrados na curva DTG para casca de coco e de castanha de caju representavam a decomposição da hemicelulose e o segundo par de picos mostrava a degradação térmica da celulose. Eles ocorreram em aproximadamente 340 e $395^{\circ} \mathrm{C}$ para a casca de castanha de caju e 329 e $400{ }^{\circ} \mathrm{C}$ para a casca de coco.

Os picos encontrados para a degradação térmica do endocarpo do ouricuri ocorreram aproximadamente em $277^{\circ} \mathrm{C}$ e $323^{\circ} \mathrm{C}$. Eles podem ser atribuídos à decomposição da hemicelulose e da celulose, respectivamente.

No intervalo entre 354 e $579^{\circ} \mathrm{C}$, a perda de massa pode ser atribuída à perda de lignina. Em seguida, observa-se uma estabilização da curva, com perda mínima de massa.

\subsection{Influência da Temperatura nos rendimentos dos produtos de pirólise}

$\mathrm{O}$ esquema representativo mostrado na Figura 5 mostra os produtos obtidos através da carbonização do endocarpo do ouricuri: carvão, mistura líquida (fase aquosa e bioóleo) e gases incondensáveis.

$\mathrm{O}$ efeito das temperaturas de carbonização nos rendimentos dos produtos de pirólise é mostrado na Figura 6. A partir dessa figura pode-se observar uma diminuição abrupta do rendimento de carvão quando a temperatura de carbonização aumentou de 400 para $500^{\circ} \mathrm{C}$ (resultado de acordo com a curva TG, conforme a Figura 4). E, em seguida, houve uma diminuição gradual do rendimento. A elevação da temperatura de 400 para $700^{\circ} \mathrm{C}$, levou o rendimento de 50,5 para $31,7 \%$. Com o aumento da temperatura, mais voláteis são liberados, provocando uma redução no rendimento de carvão (LI et al., 2008). De acordo com Soletti, Carvalho e Ellis (2012) quanto maior for a temperatura de carbonização maior será a perda de carbono na forma de compostos voláteis, pois a hemicelulose, a celulose e a lignina são degradadas.

$\mathrm{O}$ rendimento da mistura líquida e o de gases, elevou-se de $37,7 \%$ a $46,8 \%$ e $11,8 \%$ a $19,2 \%$, respectivamente, de acordo com o crescimento de temperatura- de $400^{\circ} \mathrm{C}$ a $600^{\circ} \mathrm{C}$. Quando a temperatura supera os $600^{\circ} \mathrm{C}$, o rendimento de líquido diminui ao passo que o de gases continua a aumentar, isso se deve ao craqueamento dos vapores condensáveis devido ao aumento de temperatura, fazendo com que sejam obtidos mais gases incondensáveis resultantes dessas quebras.

Vale ressaltar, que devido a problemas encontrados no sistema experimental, ocorreram algumas falhas na coleta dos gases 
condensáveis, prejudicando desta forma a estimativa real de seu rendimento.

Figura 5 - Esquema representativo do processo de pirólise estudado.

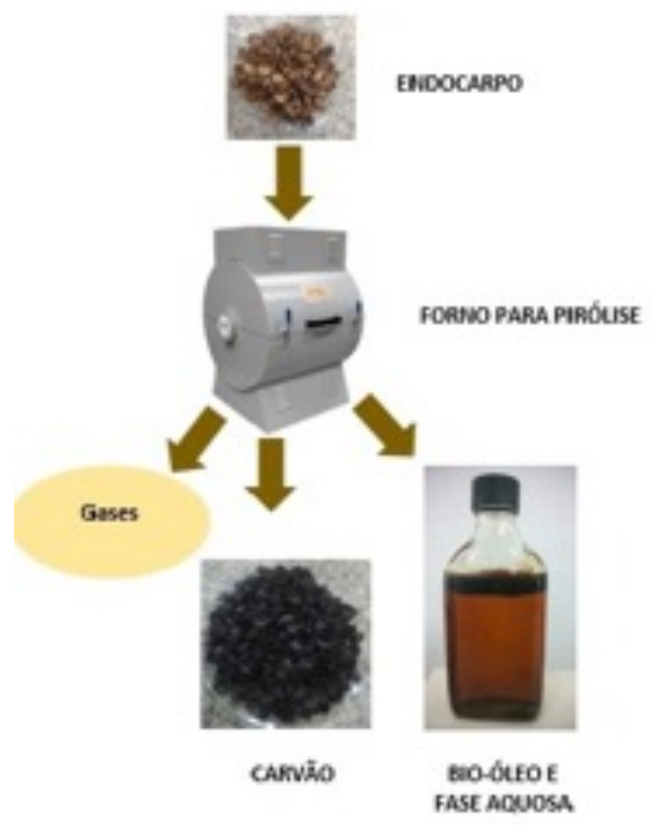

Fonte: Autor (2015).

Figura 6 - Efeito das temperaturas de carbonização nos rendimentos dos produtos.

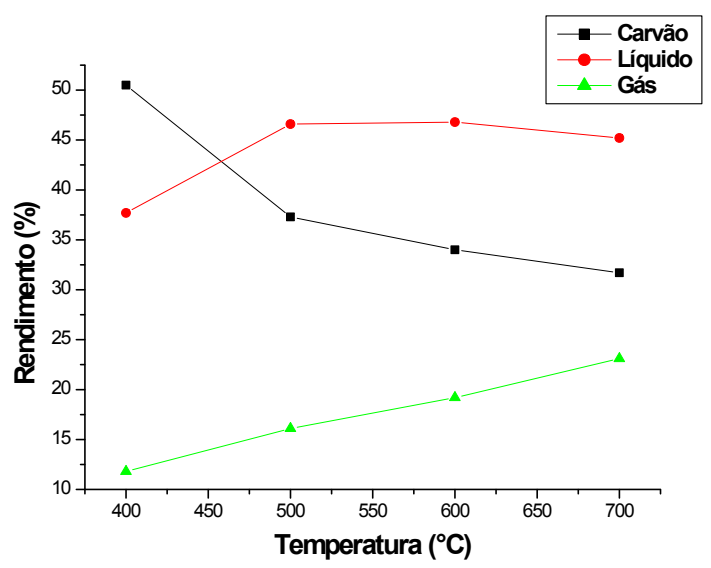

\section{CONCLUSÃO}

$\mathrm{O}$ aumento de temperatura no processo de pirólise do endocarpo do ouricuri levou a uma redução no rendimento do carvão, de 50,5 para $31,7 \%$, quando elevou-se a temperatura de 400 para $700^{\circ} \mathrm{C}$. Essa redução foi abrupta quando a temperatura passou de 400 para $500^{\circ} \mathrm{C}$, apresentando uma redução gradual com a elevação da temperatura.

$\mathrm{O}$ rendimento de gases cresceu com a elevação da temperatura, resultado da maior liberação de voláteis. Enquanto o rendimento da mistura líquida aumentou de 37,7\% para $46,8 \%$ com a elevação de temperatura de $400^{\circ} \mathrm{C}$ a $600^{\circ} \mathrm{C}$. No entanto, na temperatura de $700^{\circ} \mathrm{C}$ observou-se uma redução no rendimento de líquido e aumento no de gases incondensáveis, resultado do craqueamento dos vapores condensáveis, devido à elevação de temperatura, consequentemente fazendo com que fossem obtidos mais gases incondensáveis resultantes dessas quebras.

\section{NOMENCLATURA}

M Mf: massa líquida, em gramas, obtida pela condensação de gases após a pirólise.

$\mathbf{M}_{\mathrm{i}}$ : massa sólida, em gramas, inicial.

Msf: massa sólida final, obtida após a pirólise;

$\mathbf{R}_{\mathbf{g}}$ : rendimento de gases.

$\mathbf{R}_{\mathbf{s}}$ : rendimento de sólidos.

$\mathbf{R}_{\mathbf{I}}$ : rendimento de líquidos.

\section{REFERÊNCIAS}

BIOWARE. A Bioware. 2014. Disponível em: < http://www.bioware.com.br/conteudo/1 /bioware.aspx>. Acesso em: 16 jun. 2015.

BRIDGWATER, A. V. Review of fast pyrolysis of biomass and product upgrading. Biomass and Bioenergy, v. 38, p. 68 - 94, mar. 2012.

CORTEZ, L. A. B; LORA, E. E. S.; AYARZA, J. A.C. Biomassa no Brasil e no 
mundo. In: CORTEZ, L. A. B.; LORA, E. E.; GÓMEZ, E. O. Biomassa para energia. Campinas, SP: Editora da Unicamp, 2008.

CREPALDI, I. C.; ALMEIDA-MURADIAN, L. B.; RIOS, M. D. G.; PENTEADO, M. V. C.; SALATINO, A. Composição nutricional do fruto de licuri (Syagrus coronata (Martius) Beccari). Revta brasil. Bot., São Paulo, v.24, n.2, p.155-159, jun. 2001.

FIGUEIREDO, A. L. Pirólise termoquímica de pós da fibra de coco seco em um reator de cilindro rotativo para produção de bioóleo. 2011. 113 p. Dissertação (Mestrado em Ciência e Engenharia do Petróleo). Universidade Federal do Rio Grande do Norte, Natal, 2011.

LEHMANN, J.; JOSEPH, S. Biochar for environmental management: An Introduction. In: LEHMANN, J.; JOSEPH, S. Biochar for environmental management: science and technology. 1st ed. London: Earthscan, 2009. p. 1-9. Disponível em: < http://www.biocharinternational.org/projects/book $>$. Acesso em: 13 jan. 2015.

LI, W.; YANG, K.; PENG, J.; ZHANG, L.; GUO, S.; XIA, H. Effects of carbonization temperatures on characteristics of porosity in coconut shell chars and activated carbons derived from carbonized coconut shell chars. Industrial Crops and Products, v. 28, p.190-198, 2008.

RAMALHO, C. I. Estrutura da vegetação e distribuição espacial do Licuri (syagrus coronata (mart) becc.) em dois municípios do centro norte da Bahia. 2008. 131 p. Tese (Doutorado em Agronomia) Universidade Federal da Paraíba, Areia, 2008.
RUFINO, M. U. L.; COSTA, J. T. M.; SILVA, V.A.; ANDRADE, L. H. C. Conhecimento e uso do ouricuri (Syagrus coronata) e do babaçu (Orbignya phalerata) em Buíque, PE, Brasil. Acta bot. bras., v. 22, n. 4, p. 1141-1149, 2008.

SANTOS, K. G. Aspectos fundamentais da pirólise de biomassa em leito de jorro: fluidodinâmica e cinética do processo. 2011. 235 p. Tese (Doutorado em Engenharia Química) - Universidade Federal de Uberlândia, Uberlândia, MG, 2011.

SANTOS-MOURA, S. S. Morfologia de frutos, diásporos, plântulas, mudas e cultivo in vitro de embriões zigóticos de Syagrus coronata (Mart.) Becc. 2013. 73 p. Dissertação (Mestrado em Produção Agrícola) - Universidade Federal Rural de Pernambuco, Garanhuns, 2013.

SOLETTI, J. I.; CARVALHO, S. H. V.; ELLIS, N. Produção de biocarvão (biochar) objetivando a produção de fertilizantes. In: Congresso Brasileiro de Engenharia Química, XIX, 2012, Búzios. Anais... Búzios, 2012.

TSAMBA, A. J.; YANG, W.; BLASIAK, W. Pyrolysis characteristics and global kinetics of coconut and cashew nut shells. Fuel Processing Technology. v. 87. p. 523-530. jun. 2006.

\section{AGRADECIMENTOS}

Agradecemos a CAPES e a CNPq pelo financiamento concedido a fim de promover incentivo à pesquisa, ao Engenheiro Químico Kleber Jean e ao técnico do LASSOP e graduando em Engenharia Química Felipe Duarte por suas contribuições. 